\title{
Feasibility of a randomized controlled trial to assess treatment of Middle East Respiratory Syndrome Coronavirus (MERS-CoV) infection in Saudi Arabia: a survey of physicians
}

Yaseen M. Arabi ${ }^{*}$, Farhan Al-Enezi ${ }^{1}$, Kajsa-Stina Longuere ${ }^{2,10}$, Hanan H. Balkhy ${ }^{3}$, Mohamed Al-Sultan ${ }^{4}$, Awad Al-Omari ${ }^{5}$, Fahad M. Al-Hameed ${ }^{6}$, Gail Carson ${ }^{2,10}$, Nahoko Shindo ${ }^{7}$ and Robert Fowler ${ }^{8,9}$

\begin{abstract}
Background: The Middle East Respiratory Syndrome coronavirus (MERS-CoV) is an emerging respiratory pathogen with a high mortality rate and no specific treatments available to date. The purpose of this study was to determine the feasibility of conducting a randomized controlled trial (RCT) of convalescent plasma therapy for MERS-CoV-infected patients by using MERS-CoV-specific convalescent plasma obtained from previously recovered patients.

Methods: A survey was adapted from validated questionnaire originally aimed to measure network capacities and capabilities within the International Severe Acute Respiratory and emerging Infection Consortium (ISARIC). The questionnaire was modified for this study to include 26 items that were divided into three main domains of interest: (1) the ability to care for critically ill MERS-CoV patients; (2) laboratory capacity to diagnose MERS-CoV and blood bank ability to prepare convalescent plasma; and (3), research capacity to conduct randomized controlled trials. The questionnaire was emailed to physicians.

Results: Of 582 physicians who were invited to the survey, 327 responded (56.2\%). The professional focus of the majority of respondents was critical care (106/249 (43\%)), pediatrics (59/249, (24\%)) or internal medicine (52/249 (21 \%)) but none was blood banking. Nearly all respondents (251/263 (95\%)) reported to have access to ICU facilities within their institutions. Most respondents (219/270 (81 \%)) reported that intensivists were the most physician group responsible for treatment decisions about critically ill SARI patients. While 125/165 respondents (76 \%) reported that they conduct research in ICUs, and 80/161 (49.7\%) had been involved in the conduct of RCTs, including using a placebo comparison (60/161 (37\%)), only 49/226 (21\%) of respondents regularly participated in research networks.

Conclusions: Our survey indicated that in the Kingdom of Saudi Arabia (KSA), ICUs are the most likely clinical locations for conducting a clinical trial of convalescent plasma therapy for MERS-CoV, and that most ICUs have experience with such research designs.
\end{abstract}

Keywords: Middle East respiratory syndrome coronavirus (MERS-CoV), Convalescent plasma, Randomized controlled trial

\footnotetext{
* Correspondence: arabi@ngha.med.sa

${ }^{1}$ Intensive Care Department, King Saud bin Abdulaziz University for Health

Sciences, King Abdullah International Medical Research Center, PO Box

22490, Riyadh 11426, Saudi Arabia

Full list of author information is available at the end of the article
} 


\section{Background}

A novel coronavirus was first diagnosed in Saudi Arabia in June 2012 in a man who presented with pneumonia and acute renal failure [1]. This newly discovered virus leading to severe pneumonia and acute respiratory distress syndrome (ARDS) was later named Middle East respiratory syndrome coronavirus (MERS-CoV). As of July 3, 2016, there have been 1769 laboratoryconfirmed cases of MERS-CoV infection, $85 \%$ of which occurred in the Kingdom of Saudi Arabia [2]. The case fatality rate is $35 \%$ and reaches $70 \%$ in critically ill patients [3] with no specific therapy available to date.

Convalescent plasma that contains MERS-CoV-specific immunoglobulin and is obtained from previously recovered patients has been suggested as a potential therapy for patients with MERS-CoV infection. Convalescent plasma has been used to treat several other viral infections, including the Severe Acute Respiratory Syndrome (SARS) SARS coronavirus (SARS-CoV), Spanish influenza A (H1N1), avian influenza A (H5N1), and 2009 pandemic influenza A (H1N1 pdm09) [4-10]. A recent meta-analysis of observational studies of passive immunotherapy in SARS and severe influenza suggest reductions in mortality with timely use of convalescent blood products, particularly those with neutralizing antibodies [11]. Public Health England and the International Severe Acute Respiratory \& Emerging Infection Consortium (ISARIC) have published a decision-support tool for clinicians managing cases of MERS-CoV infection [12], which relies heavily upon expert opinion and clinical experience of treating patients with severe respiratory disease caused by other viruses including SARS and 2009 pandemic influenza A (H1N1pdm09). The document suggests that current evidence is strongest for testing convalescent plasma (CP) or other therapeutics which contain neutralizing antibodies (such as hyperimmune immunoglobulin) for treatment of serious MERS-CoV illness.

Given the scattered distribution of cases in Saudi Arabia, it is unclear whether the clinical and research infrastructure would be sufficient to support the conduction of a randomized controlled trial (RCT) of convalescent plasma therapy. Such a study will require laboratory ability to diagnose MERS-CoV infection and identify antibody titers among previously infected but recovered patients, research infrastructure and ability to lead or participate in an RCT, and the presence of personal and community equipoise among healthcare workers and patients to enroll in such a trial. Therefore, as part of a collaborative effort among colleagues from the Gulf States and Eastern Mediterranean and with the support of the World Health Organization and International Severe Acute Respiratory and Emerging Infection Consortium, we undertook a survey to assess feasibility of conducting a clinical trial of convalescent plasma therapy for patients with MERS-CoV infection in KSA.

\section{Methods \\ Study population}

The study targeted health care specialists in internal medicine, critical care, respiratory disease, infectious disease, hematology, and pediatrics, along with clinical microbiologists, hospital epidemiologists and blood bankers. The survey consisted of voluntary anonymous responses to a web-based questionnaire and did not include actual patient data.

\section{Questionnaire development}

A validated questionnaire, previously used by ISARIC to evaluate and map capacity conduct of clinical trials in response to outbreaks, was used as a basis for the development of this survey. Omitting questions that were deemed not relevant to this study, and modifying or adding questions that were more appropriate to the current objectives led to a questionnaire of 26 items, divided into three main domains of interest. First, four questions aimed to evaluate the ability and capacity of caring for critically ill patients within the KSA health system (e.g., "How many beds are capable of caring for mechanically ventilated patients in the ICU where patients with severe acute respiratory infection (SARI) would usually be treated?"). Second, the study sought to explore laboratory capacity to diagnose MERS-CoV infection and Blood Bank ability to prepare convalescent plasma through seven questions (e.g., "Do you have a mechanism to send specific blood donors (e.g., survivors of MERS-CoV infection) to the blood bank to make donations?" and "What methodologies are available in the laboratories associated with your site for MERS-coV testing?"). The third domain aimed to evaluate research capacity needed to conduct clinical trials and whether or not necessary infrastructure to conduct RCTs existed in KSA, through 10 questions specifically related to research (e.g., "Do you believe that patients at your hospital would participate in randomized studies in which patients are randomly assigned to one of two or more treatments?"). The questionnaire was populated using Survey Monkey, was emailed through the snowball methodology, to physicians who are possibly involved in the care of MERS-CoV patients. Snowball sampling is a chain referral sampling where the initial participants are asked to assist in recruiting more subjects by passing on the questionnaire. We initiated contact with 250 participants from 48 hospitals in Saudi Arabia; those in turn invited others, with a total subjects approached being approximately 582 . There were three reminders, 2 weeks apart by email to non-respondents, and the data was collected between March and May 2014. A complete list of 
the survey questions is included in the online supplement (Additional file 1). The Institutional Review Board (IRB) of Ministry of National Guard Health Affairs (RC14/003/R29 April 2015) approved this study. The first question of the survey was a question about whether the participant consents to the survey.

\section{Statistical analysis}

Descriptive statistics (frequencies and percentages) were used to quantify the categorical study variables.

\section{Results}

\section{ICU capacity}

Of 582 physicians who were invited to the survey, 327 responded (56.2\%) (Table 1). The professional focus of the majority of respondents was critical care (106/249 $(43 \%))$, pediatrics $(59 / 249(24 \%))$ or internal medicine $(52 / 249(21 \%))$ but none was blood banking. Nearly all respondents $(251 / 263,95 \%)$ reported to have access to ICU facilities within their institutions and $44 \%$ of these
ICUs had more than 20 beds. Most respondents (219/ $270(81 \%))$ reported that intensivists were the most physician group responsible for treatment decisions about critically ill SARI patients. Available reported therapies in the ICUs included extra-corporal membrane oxygenation (ECMO) $(48 \%)$, hemodialysis $(91 \%)$ and plasmapheresis (82\%).

\section{Laboratory capacity}

Majority of the respondents (235/250 (94\%)) indicated that blood products used in their hospitals were obtained in the same hospital, only 15/250 (6\%) reported that blood products are obtained from a blood bank at another institution. When asked about the feasibility of having MERS-CoV infection survivors to donate blood/ plasma, 130/237 (55 \%) of the respondents reported this would be feasible (Table 2). A majority (240/248 (97\%)) of the respondents reported to have access to the necessary facilities and capabilities for screening for blood-borne viruses in donated blood within their

Table 1 Respondent and ICU characteristics

\begin{tabular}{|c|c|c|c|}
\hline Questions & Responders to the Question & Answer options & Responder \\
\hline \multirow[t]{9}{*}{ The professional focus of the respondents ${ }^{\mathrm{a}}$} & \multirow[t]{9}{*}{249} & Critical care & $106(42.5)$ \\
\hline & & Pediatrics & $59(23.6)$ \\
\hline & & Internal medicine & $52(20.9)$ \\
\hline & & Respiratory & $37(14.8)$ \\
\hline & & Infectious diseases & 34 (13.6) \\
\hline & & Microbiology or virology & $7(2.8)$ \\
\hline & & Hematology & $7(2.8)$ \\
\hline & & Blood bank & 0 \\
\hline & & Other & $52(20.9)$ \\
\hline The presence of ICU in the hospital ${ }^{b}$ & 263 & Yes & $251(95.4)$ \\
\hline \multirow{5}{*}{$\begin{array}{l}\text { Number of ICU beds capable of caring for mechanically } \\
\text { patients ventilated with SARI }\end{array}$} & \multirow[t]{5}{*}{285} & $0-5$ & $37(12.9)$ \\
\hline & & $6-10$ & $47(16.4)$ \\
\hline & & $11-20$ & $61(21.4)$ \\
\hline & & $>20$ & $125(43.8)$ \\
\hline & & Unsure & $15(5.2)$ \\
\hline \multirow[t]{4}{*}{ Specific therapies available in the ICU } & \multirow[t]{4}{*}{259} & Extra-corporeal membrane oxygenation (ECMO) & $125(48.2)$ \\
\hline & & Hemodialysis & $235(90.7)$ \\
\hline & & Plasmapheresis and/or plasma exchange & $212(81.8)$ \\
\hline & & Care to pediatric patients & $222(85.7)$ \\
\hline \multirow{6}{*}{$\begin{array}{l}\text { The most responsible physician group for treatment } \\
\text { decisions about critically ill patients }\end{array}$} & \multirow[t]{6}{*}{270} & Intensivists & $219(81.1)$ \\
\hline & & Pulmonologists & $17(6.2)$ \\
\hline & & Infectious diseases specialists & $17(6.2)$ \\
\hline & & Anesthesiologists & $9(3.3)$ \\
\hline & & Surgeons & $1(0.3)$ \\
\hline & & Other & $7(2.5)$ \\
\hline
\end{tabular}

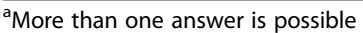

${ }^{\mathrm{b}} \mathrm{ICU}$ is defined as a geographic location in the hospital where patients with severe acute respiratory infection (SARI) can be treated with invasive mechanical ventilation 
Table 2 Laboratory capacity questions

\begin{tabular}{|c|c|c|c|c|}
\hline Questions & Responders to the Question & Answer options & Responders & \\
\hline \multirow[t]{2}{*}{ The source of blood products? } & \multirow[t]{2}{*}{250} & Blood bank in your facility & \multicolumn{2}{|l|}{$235(94.0)$} \\
\hline & & Blood bank from another facility & \multicolumn{2}{|l|}{$15(6.0)$} \\
\hline $\begin{array}{l}\text { Feasibility of obtaining blood donation from specific groups } \\
\text { (e.g., survivors of MERS-CoV) }\end{array}$ & 237 & Yes & \multicolumn{2}{|l|}{$130(54.9)$} \\
\hline $\begin{array}{l}\text { The capability to screen for blood-borne viruses in donated } \\
\text { blood (e.g., HIV, hepatitis, etc.)? }\end{array}$ & 248 & Yes & \multicolumn{2}{|l|}{$240(96.8)$} \\
\hline $\begin{array}{l}\text { Ability to send suspected MERS-CoV samples to a reference } \\
\text { laboratory for diagnosis? }\end{array}$ & 226 & Yes & \multicolumn{2}{|l|}{$173(76.5)$} \\
\hline \multirow[t]{12}{*}{ Turn-around time } & \multirow[t]{12}{*}{164} & 1 day & \multicolumn{2}{|l|}{15} \\
\hline & & 2 days & \multicolumn{2}{|l|}{24} \\
\hline & & 3 days & \multicolumn{2}{|l|}{44} \\
\hline & & 4 days & \multicolumn{2}{|l|}{15} \\
\hline & & 5 days & \multicolumn{2}{|l|}{24} \\
\hline & & 6 days & \multicolumn{2}{|l|}{3} \\
\hline & & 7 days & \multicolumn{2}{|l|}{22} \\
\hline & & 9 days & \multicolumn{2}{|l|}{1} \\
\hline & & 10 days & \multicolumn{2}{|l|}{7} \\
\hline & & 14 days & \multicolumn{2}{|l|}{6} \\
\hline & & 15 days & \multicolumn{2}{|l|}{1} \\
\hline & & 21 days & \multicolumn{2}{|l|}{2} \\
\hline \multirow[t]{10}{*}{ Methodologies for MERS-CoV testing ${ }^{a}$} & \multirow[t]{10}{*}{205} & \multirow[t]{3}{*}{ Real-time PCR } & Yes & 135 \\
\hline & & & No & 10 \\
\hline & & & Do not know & 57 \\
\hline & & \multirow[t]{3}{*}{ Sequencing } & Yes & 22 \\
\hline & & & No & 21 \\
\hline & & & Do not know & 110 \\
\hline & & \multirow[t]{3}{*}{ Serology } & Yes & 51 \\
\hline & & & No & 21 \\
\hline & & & Do not know & 88 \\
\hline & & Other (please specify) & & 8 \\
\hline \multirow{10}{*}{$\begin{array}{l}\text { Available diagnostic work-up for severe acute } \\
\text { respiratory infection }\end{array}$} & \multirow[t]{10}{*}{218} & Blood cultures & Yes & 205 \\
\hline & & & No & 4 \\
\hline & & & Do not know & 6 \\
\hline & & Urine bacterial antigen testing & Yes & 153 \\
\hline & & & No & 28 \\
\hline & & & Do not know & 30 \\
\hline & & Viral antigen testing & Yes & 146 \\
\hline & & & No & 36 \\
\hline & & & Do not know & 28 \\
\hline & & PCR for bacterial and viral testing & Yes & 170 \\
\hline
\end{tabular}

${ }^{\text {a }}$ More than one answer is possible

institutions. In regards to laboratory testing for MERSCoV, 173/226 (77 \%) reported that samples for MERS$\mathrm{CoV}$ testing were sent to reference laboratories for diagnosis, with 147/164 (90\%) reported that the results were obtained within seven days. Other microbiologic tests for pneumonia work-up were reported to be available as follows: $95 \%$ blood cultures, $73 \%$ for urine bacterial antigen testing, $70 \%$ for viral antigen testing, and $79 \%$ for PCR 
Table 3 Research capacity questions

\begin{tabular}{|c|c|c|c|}
\hline Questions & Responders & Answer options & Responders \\
\hline $\begin{array}{l}\text { Regular participation of the respondent in a specific } \\
\text { research network(s)? }\end{array}$ & 226 & Yes & $49(21.7)$ \\
\hline \multirow[t]{5}{*}{ The predominant focus of the network ${ }^{\mathrm{a}}$} & \multirow[t]{5}{*}{114} & Clinical infectious diseases & $46(40.3)$ \\
\hline & & Microbiology or virology & $24(21.0)$ \\
\hline & & Critical care & $71(62.2)$ \\
\hline & & Public or global health & $34(29.8)$ \\
\hline & & Other (please specify) & $11(9.6)$ \\
\hline \multirow[t]{3}{*}{ Participation in research initiatives ${ }^{a}$} & \multirow[t]{3}{*}{148} & Local clinical research initiatives & $130(87.8)$ \\
\hline & & National clinical research initiatives & $67(45.3)$ \\
\hline & & International clinical research initiatives & $55(37.2)$ \\
\hline \multirow{2}{*}{$\begin{array}{l}\text { Age categories of patients are recruited into studies } \\
\text { at the respondent site }\end{array}$} & \multirow[t]{2}{*}{165} & Adult & $139(84.2)$ \\
\hline & & Pediatrics & $56(33.9)$ \\
\hline \multirow[t]{5}{*}{ Settings in the hospital that conduct clinical research ${ }^{a}$} & \multirow[t]{5}{*}{165} & Emergency department & $66(40.0)$ \\
\hline & & Hospital wards & $104(63.0)$ \\
\hline & & ICUs & $125(75.8)$ \\
\hline & & Outpatient/community care settings & $75(45.5)$ \\
\hline & & Other & $5(3.0)$ \\
\hline \multirow[t]{5}{*}{ Research types in the respondent hospital ${ }^{a}$} & \multirow[t]{5}{*}{161} & Retrospective observational studies ${ }^{b}$ & $147(91.3)$ \\
\hline & & Prospective observational studies & $115(71.4)$ \\
\hline & & Biological sampling studies (blood and other fluids) & $79(49.1)$ \\
\hline & & Randomized clinical trials of interventions & $80(49.7)$ \\
\hline & & Clinical trials using a placebo control comparison group & $60(37.3)$ \\
\hline \multirow{5}{*}{$\begin{array}{l}\text { Do you believe that patients at your hospital would } \\
\text { participate in randomized studies? }\end{array}$} & \multirow[t]{5}{*}{181} & Definitely not & $8(4.4)$ \\
\hline & & Probably not & $31(17.1)$ \\
\hline & & Maybe & $70(38.7)$ \\
\hline & & Probably yes & $49(27.1)$ \\
\hline & & Definitely & $23(12.7)$ \\
\hline $\begin{array}{l}\text { The presence of registry data (i.e., an electronic or } \\
\text { hard-copy database) }\end{array}$ & 179 & Yes & $146(81.6)$ \\
\hline
\end{tabular}

${ }^{a}$ More than one answer is possible

${ }^{b}$ Retrospective observational studies include case reports, chart review case series, case-control studies, cohort studies

for bacterial and viral testing. Respondents reported that the most commonly available diagnostic test was real-time PCR (67\%) and the least available methodology was gene sequencing (14\%).

\section{Research capacity}

Most respondents reported involvement in local clinical research initiatives ( $88 \%$ ) while only $21 \%$ of respondents claimed to be part of specific research networks, predominantly focused upon clinical infectious diseases and critical care and the focus of investigation was mostly (84 \%) upon adults. Most research $(76 \%)$ is perceived to take place in ICUs (76 \%) and hospital wards (63 \%) (Table 3). Of the physicians surveyed, $91 \%$ worked at hospitals that have participated in retrospective observational studies, while $71 \%$ reported being involved in prospective studies or trials. Only half of the respondents (49\%) perceived their institutions had been involved with biological sampling studies (of blood and other fluids) or randomized clinical trials of interventions (50\%), while only $37 \%$ knew of their institutions having been involved in clinical trials using a placebo control comparison group.

A majority 146/179 (82\%) of respondents said that they had access to registry data for patients receiving care at their sites, and more than $50 \%$ of respondents reported that their institutions had a research administration infrastructure in place to aid with data-sharing agreements (52\%), research contract (49\%), ethics reviews (74\%), and administrative support for research projects $(60 \%)$. The 
average time for the ethical review process (from submission to approval to enroll patients) was approximately 1 to 3 months.

Although $22 \%$ of respondents said that the patients at their hospital were definitely not or probably not likely to participate in randomized studies and $39 \%$ said that they were 'maybe' prepared to parttake in such studies, $40 \%$ of respondents said they believed their patients would probably or definitely agree to participate.

\section{Discussion}

Our survey identifies that many healthcare facilities in KSA have the necessary capacity to participate RCTs that enroll severely ill patients with MERS-CoV infection. The survey highlights a few important points in support of this conclusion. First, most respondents believed that the needed infrastructure was in place - such as data registries, laboratory capacity, ethics review processes, and monitoring units for RCTs. Second, respondents seemed to be aware of the required capacity for research in MERS-CoV. Third, although not the most common trial design in Saudi Arabia, most respondents were aware of RCTs and what they entail, and a majority of them believed that their patients would consider participating in RCTs. However, many barriers to conducting RCTs remain. First, there is low community awareness of research in general, which is needed for any RCT to take place. Second there may be lengthy processes required to obtain regulatory and ethics approval to initiate clinical trials.

This survey suggests that the necessary clinical and laboratory facilities exist to conduct such RCTs. The presence of ICUs with sufficient numbers of beds is a necessary component of conducting RCTs on potential therapies for critically ill patients with MERS-CoV. Essential laboratory infrastructure for such studies are also available including blood banking, microbiologic diagnostic testing for pneumonia in general and MERS-CoV in particular. However, as none of the respondents was a blood bank specialist, it is not possible to explore this in greater detail on the basis of this survey alone. A majority of the respondents (54.9\%) reported that sending individuals who had recovered from MERS-CoV to donate blood is feasible, which is a positive and necessary step for obtaining convalescent plasma.

There are a number of limitations associated with this study. Because of the snowball methodology, the number of subjects who were approached is only approximate. Response rate was modest, and response rates to individual questions varied. Due to the anonymity of replies to this survey it has not been possible to follow up on incomplete responses. There were no responses from blood banks. As with other surveys, it is possible that individuals motivated to conduct research or work in institutions that conduct research were more likely to respond to the survey; creating a bias towards more favorable answers for research infrastructure and culture. The study did not include a face-to-face interview, which would have resulted in higher targeted responses. Finally, surveys represent stated responses as opposed to measurement of actual practice.

\section{Conclusions}

Our survey results indicate that the research infrastructure at many acute care facilities in Saudi Arabia is likely generally sufficient to conduct a RCT to investigate the efficacy of convalescent plasma treatment for severely ill patients with MERS-CoV. Next steps in such a research program will need to include an observational study of actual clinical and diagnostic practice in the care of patients with MERS-CoV in KSA. This would help to inform design of a pilot clinical trial with a goal to demonstrate feasibility and safety of convalescent plasma evaluation, and would need to occur before a true evaluation of efficacy could take place.

\begin{abstract}
Abbreviations
$\mathrm{CP}$, convalescent plasma; $\mathrm{ECMO}$, extra corporal membrane oxygenation; HCW, health care workers; ICU, intensive care unit; ISARIC, International Severe Acute Respiratory \& Emerging Infection Consortium; KSA, Kingdom of Saudi Arabia; MERS-CoV, Middle East respiratory syndrome coronavirus; $\mathrm{PCR}$, polymerase chain reaction; $R C T$, randomized controlled trial; SARI, severe acute respiratory infection; SARS, severe acute respiratory syndrome; WHO, World Health Organization
\end{abstract}

\section{Additional file}

Additional file 1: Severe Acute Respiratory Infection Survey for Regions affected by Middle Eastern Respiratory Syndrome Coronavirus (MERS-CoV) (DOC $238 \mathrm{~kb}$ )

\begin{abstract}
Acknowledgements
Not applicable.

Funding

Not applicable.

Availability of data and materials

Not applicable.

Authors' contributions

YA: Conception and design, analytical plan, drafting of the manuscript, critical revision of the manuscript for important intellectual content, approval of the final version to be published. FA, HB: Conception, drafting of the manuscript, critical revision of the manuscript for important intellectual content, approval of the final version to be published. KL, MS, AO, FA, GC and NS: Conception, critical revision of the manuscript for important intellectual content, approval of the final version to be published. RF: Design, statistical plan, critical revision of the manuscript for important intellectual content, approval of the final version to be published.
\end{abstract}

\section{Competing interests}

The authors declare that they have no competing interests.

Consent for publication

Not applicable. 


\section{Ethics approval and consent to participate}

The Institutional Review Board (IRB) of Ministry of National Guard Health Affairs (RC14/003/R-29 April 2015) approved this study and the first question of the survey was a question about whether the participant consents for the survey.

\section{Disclaimer}

Nahoko Shindo is a staff member of the World Health Organization. The author alone is responsible for the views expressed in this article and they do not necessarily represent the decisions, policy or views of the World Health Organization.

\section{Author details}

'Intensive Care Department, King Saud bin Abdulaziz University for Health Sciences, King Abdullah International Medical Research Center, PO Box 22490, Riyadh 11426, Saudi Arabia. ${ }^{2}$ University of Oxford Centre for Tropical Medicine (CCVTM), Churchill Hospital Old Road, Headington, Oxford OX3 7LE, UK. ${ }^{3}$ Infection Control Department, King Saud bin Abdulaziz University for Health Sciences, King Abdullah International Medical Research Center, Riyadh, Saudi Arabia. ${ }^{4}$ Emergency \& Critical Care Medicine, King Saud bin Abdulaziz University for Health Sciences, King Abdullah International Medical Research Center, Riyadh, Saudi Arabia. ${ }^{5}$ AlFaisal University, Riyadh, Saudi Arabia. ${ }^{6}$ Critical Care \& Pulmonary Medicine, King Saud bin Abdulaziz University for Health Sciences, King Abdulaziz Medical City, Jeddah, Saudi Arabia. ${ }^{7}$ Pandemic and Epidemic Diseases Department, World Health Organization, Geneva, Switzerland. ${ }^{8}$ Department of Medicine and Institute of Health Policy Management and Evaluation, University of Toronto, Toronto, Canada. ${ }^{9}$ Department of Medicine and Interdepartmental Division of Critical Care Medicine, Sunnybrook Health Sciences Centre, Toronto, Canada. ${ }^{10}$ International Severe Acute Respiratory \& emerging Infection Consortium (ISARIC), Old Road Campus, Headington OX3 7FZ, UK.

Received: 15 July 2015 Accepted: 28 May 2016

Published online: 12 July 2016

\section{References}

1. Zaki AM, van Boheemen S, Bestebroer TM, Osterhaus AD, Fouchier RA Isolation of a novel coronavirus from a man with pneumonia in Saudi Arabia. N Engl J Med. 2012;367(19):1814-20.

2. Middle East respiratory syndrome coronavirus (MERS-CoV) - Saudi Arabia: http://www.who.int/csr/don/2-february-2016-mers-saudi-arabia/en/. Accessed 3 July 2016.

3. Arabi YM, Arifi AA, Balkhy HH, Najm H, Aldawood AS, Ghabashi A, Hawa H, Alothman A, Khaldi A, Al Raiy B. Clinical course and outcomes of critically ill patients with Middle East respiratory syndrome coronavirus infection. Ann Intern Med. 2014;160(6):389-97.

4. Hung IF, To KK, Lee CK, Lee KL, Yan WW, Chan K, Chan WM, Ngai CW, Law Kl, Chow FL, et al. Hyperimmune IV immunoglobulin treatment: a multicenter double-blind randomized controlled trial for patients with severe 2009 influenza A(H1N1) infection. Chest. 2013;144(2):464-73.

5. Stockman LJ, Bellamy R, Garner P. SARS: systematic review of treatment effects. PLoS Med. 2006:3(9):e343.

6. Hung IF, To KK, Lee CK, Lee KL, Chan K, Yan WW, Liu R, Watt CL, Chan WM, Lai KY, et al. Convalescent plasma treatment reduced mortality in patients with severe pandemic influenza A (H1N1) 2009 virus infection. Clin Infect Dis. 2011;52(4):447-56.

7. Luke TC, Kilbane EM, Jackson JL, Hoffman SL. Meta-analysis: convalescent blood products for Spanish influenza pneumonia: a future H5N1 treatment? Ann Intern Med. 2006;145(8):599-609.

8. Centers for Disease Control and Prevention. First Confirmed Cases of Middle East Respiratory Syndrome Coronavirus (MERS-CoV) Infection in the United States, Updated Information on the Epidemiology of MERS-CoV Infection, and Guidance for the Public, Clinicians, and Public Health Authorities May 2014. MMWR. 2014;63(19):431-6. this report was posted as an MMWR Early Release on the MMWR website (http://wwwcdcgov/mmwr).

9. Cheng $Y$, Wong R, Soo YO, et al. Use of convalescent plasma therapy in SARS patients in Hong Kong. Eur J Clin Microbiol Infect Dis. 2005;24:44-6.
10. Kong LK, Zhou BP. Successful treatment of avian influenza with convalescent plasma. Hong Kong Med J. 2006;12(6):489.

11. Mair-Jenkins J, Saavedra-Campos M, Baillie JK, Cleary P, Khaw FM, Lim WS, Makki S, Rooney KD, Nguyen-Van-Tam JS, Beck CR. Convalescent Plasma Study Group. J Infect Dis. 2015;211(1):80-90. doi: 10.1093/infdis/jiu396. Epub 2014 Jul 16. Review.

12. Memish ZA, Zumla Al, Al-Hakeem RF, Al-Rabeeah AA, Stephens GM. Family cluster of Middle East respiratory syndrome coronavirus infections. N Engl J Med. 2013;368(26):2487-94.

\section{Submit your next manuscript to BioMed Central and we will help you at every step:}

- We accept pre-submission inquiries

- Our selector tool helps you to find the most relevant journal

- We provide round the clock customer support

- Convenient online submission

- Thorough peer review

- Inclusion in PubMed and all major indexing services

- Maximum visibility for your research

Submit your manuscript at www.biomedcentral.com/submit
) Biomed Central 